\section{Did the IRB Approve This?}

Drug prices and cost of care keep escalating. The Centers for Medicare \& Medicaid Services (CMS), our nation's largest payer for health care services, has legitimate concerns about curbing cost. So does everyone else.

CMS now has a new dog in the fight. In an effort to encourage the use of less expensive drugs, CMS has offered a new deal. Drugs are currently reimbursed at the Average Sales Price plus 6\% (ASP $+6 \%$ ). That 6\% (actually $4.3 \%$ because of sequestration) is meant to compensate for the cost of acquisition, storage, and other expenses associated with the safe handling of anticancer drugs. So how does $\mathrm{ASP}+2.5 \%$ PLUS a new flat payment of $\$ 16.80$ (with sequestration, $\mathrm{ASP}+.86 \%$ and $\$ 16.53)$ sound to you?

Well, if you're not sure, you can look to an analysis performed by ASCO that demonstrated that the average 15-physician practice can anticipate an average annual loss of more than $\$ 560,000$. That's more than half a million dollars no longer available to support patient care. Of course, CMS proposes to study this and has posted intent to randomize doctors around the country within geographic regions to either the old payment plan or the new one. And it's not voluntary, it's mandatory!

There is so much wrong with this. First of all, CMS has a number of projects already underway. Take the Oncology Care Model for bundled payments, for instance. Shouldn't we see how these other things work out before trying something else? And shouldn't we be concerned about the impact of such a dramatic payment change? Would patients be referred elsewhere for treatment? Such as hospital-based facilities that actually cost more? What if patients are harmed with this disruption in care? Where is the strategy to capture these adverse events?

When I conduct a study, I have to get the approval of my peers (scientific review) and then approval for patient safety and risk/benefit balance from the Institutional Review Board (IRB). And when I open the study, I need to monitor and report all adverse events. Why is this different? Shouldn't doctors and patients have the privilege of providing informed consent for something like this? And shouldn't the study be tracking more than just cost?

Let's face it. We have a broken system and we need to fix it. We don't need another workaround to try to coerce doctors to behave differently. I know it's complicated, but I think we need a legal means of challenging drug pricing, or at least a valid method of paying based on value. And CMS needs to recognize that every time a new idea surfaces, there is a cost involved in marshaling a public response to try to halt or at least more thoroughly understand the initiative.

If this change goes through, it will be applied to all practices, not just oncology. The budget-neutral design of this project means resources will be diverted from expensive diseases like cancer to specialties like primary care. Although I'm all for getting more resources to our primary care colleagues, this is not the way. And if the CMS hypothesis is correct - that physicians prescribe treatment solely because of financial incentives - have they prepared for the big jump in things like B-12 shots?

In summary, I think this experiment is a mistake and I hope CMS reconsiders the plan. I also hope CMS engages the oncology community in a productive dialogue about what we can do together going forward. We need some teamwork here!

What do you think? Please e-mail correspondence (include contact information) to JNCCN@nccn.org.

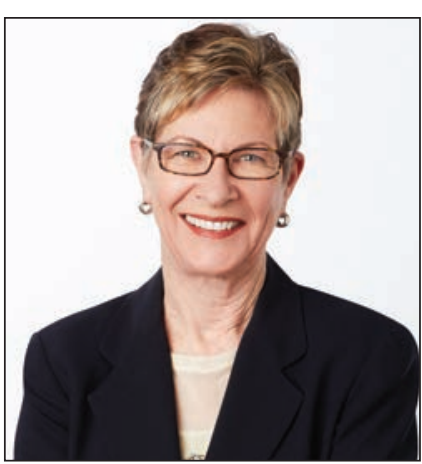

Margaret Tempero, MD

Margaret Tempero, MD, is a Professor of Medicine and Director of the UCSF Pancreas Center and editor-in-chief of JNCCN. Her research career has focused on pancreatic ductal adenocarcinoma, especially in the area of investigational therapeutics. Dr. Tempero has served on the ASCO Board of Directors and as ASCO President. She currently serves on the ASCO Conquer Cancer Foundation Board. She codirected the AACR/ASCO Methods in Clinical Cancer Research and taught this course and similar courses in Europe and Australia. She was founding Chair of the $\mathrm{NCl}$ Clinical Oncology Study Section and served as a member and Chair of the $\mathrm{NCl}$ Board of Scientific Counselors Subcommittee A. She is a member of the Scientific Steering Committee and Chair of the Clinical and Translational Study Section for the Cancer Prevention \& Research Institute of Texas. She is or has been on the Scientific Advisory Boards of the Lustgarten Foundation, the Pancreatic Cancer Action Network, the $V$ Foundation, The Alberta Canada Cancer Board, and the EORTC. She served as a member of the Oncology Drug Advisory Committee for the FDA. She has served as Deputy Director and Interim Director for the UNMC Eppley Cancer Center. She is Chief Emeritus of the Division of Medical Oncology at UCSF and served as the founding Deputy Director and Director of Research Programs at the UCSF Helen Diller Family Comprehensive Cancer Center.

The ideas and viewpoints expressed in this editorial are those of the author and do not necessarily represent any policy, position, or program of NCCN. 